\title{
RELATÓRIO DA SESSÃO DE TEMĀS LIVRES, E ENCERRAMENTO
}

Relatório da sessão de 27-10-76, presidida pelo Professor Naief Safady, da Universidade Federal de Minas Gerais.

Aberta a sessão às 8 horas e 35 minutos, fol convidada a Professora Maria Carolina Brasileiro de Castro, da Faculdade de Filosofia, Ciências e Letras de Lavras, Minas Gerais, para secretariar os trabalhos.

O Presidente da sessão agradeceu ao Reitor da Universidade Federal do Paraná, e ao coordenador Prof. Dr. David Antônio da Silva Carneiro, e transmitiu os seguintes avisos:

1.) Os certificados de participação no Encontro serāo enviados posteriormente. 2.) As comunicações e trabalhos apresentados terão sua publicaçāo na revista LETRAS, que será remetida aos participantes. 3.`) A relaçāo dos participantes com os respectivos endereços será distribuida pela organização do IV Encontro, após a presente sessão. $4 .^{\circ}$ J Os conferencistas e comunicadores deverão entregar, por escrito, o material de seus trabalhos.

Em seguida, o Presidente deu inicio à comunicação de Temas Livres, objeto da presente sessão.

Apresentaram-se, pela ordem:

$1^{\circ)}$ Professor Dr. João Déclo, da E.E.C.L. de Merília, São Paulo, que abordou o seguinte tema: Para um estudo da realldade simbólica na poesia de Herberto Helder. 
2.9) Professor Dr. Massaud Moisés, da Universidade de Säo Paulo, que apresentou proposta ao MEC e Secretarias da Educação dos Estados, solicitando providências para o cumprimento do Parecer n.: 853/71 (aprovado em 12-11-1971 e homologado pelo Sr. Ministro da Educação), sobre a Doutrina dos Curriculos. destacando-se o item dos Objetivos (proposta anexa ao presente Relatório].

Após a leitura da proposta, o Presidente consultou os presentes, sugerindo a colocaçāo em plenário da comunicaçāo do Prof. Dr. Massaud Moisés.

Intervenção do Professor Dr. Antônio Soares Amora, consignando a expressão de louvor ao trabalho do Prof. Dr. Massaud Moisés, em favor do cumprimento ao que fora proposto no III Encontro, em Recife. E sugeriu que tal proposta fosse encaminhada ao MEC, e que cada professor levasse para sua Faculdade a sugestāo de reintroduzir os autores portugueses nos programas de Vestibular.

O Presidente insistiu se o trabalho do Protessor Dr. Massaud Moisés deveria figurar como comunicação ou deliberaçäo do Plenário.

Intervençāo do Professor Dr. Antōnio Soares Amora, julgando que se deveria considerar simultaneamente comunicação e deliberaçăo.

O Presidente propôs que, os que estivessem de acordo com o documento apresentado pelo Professor Dr. Massaud Moisés, o aprovassem por aclamação, e assim foi feito.

A comunicação-deliberaçāo vai transcrita em seguida ao Relatória.

3..) Professora Consuelo M. Loureiro, de Miami University, que tratou do tema: 0 amor irrealizável em "José Matias" de Eça de Queiroz.

Ao final de sua comunicaçāo, a Professora agradeceu a hospitalidade da Universidade Federal do Paraná, especialmente ao Professor Dr. David Antônio da Silva Carneiro.

Intervençāo do Professor Dr. Antônio Soares Amora, exaltando reconhecimento e aplauso à contribuiçāo do estudo da Professora Consuelo $M$. Loureiro para o maior conhecimento da obra de Eça de Queirós.

4.) Professor Fernando Manoel de Mendonça, da E.E.C.L. de Assis, São Paulo, abicando o tema: Pós-Graduação em Llteratura Portuguesa.

Intervenção do Professor Leodegário A. de Azevedo Filho, da Universidade Estadual da Guanabara, Rio de Janeiro:

Agradeceu ao Professor Fernando Manoel de Mendonça pelo que acrescentou à sua Conferência, na 1: sessāo, de 25-10-76, sobre o mesmo tema: 


\section{P6s-Graduação em Literatura Portuguesa.}

Lembrou ainda o Professor Leodegário A. de Azevedo Filho que "a pós-graduação é mais um estado de espírito do que um estado de consciêncla, donde o seu perigo mortal".

Sugeriu, a seguir, que o Professor Fernando Manoel de Mendonça substituísse a designaçāo Literatura Africana por Llteratura de Língua Portuguesa de expressāo africana, ao que o Professor Fernando Manoel de Mendonça respondendo, citou o exemplo do escritor Manoel Ferreira, que não sendo cabo-verdiano, o é mais pela sua expressāo do que multos outros autores lá nascidos. Talvez, por essa razāo, năo seja impróprio o uso da expressão Literatura Africana. E terminou, deixando a seguinte interrogação: - "Depois que o grande alimento da Literatura Africana - a Contestaçāo - para onde val essa Literatura Africana de expressão portuguesa?".

5.) Professora Juril Nascimento Campelo, da Universidade Federal do Paraná, que apresentou o seguinte tema: A caracterlzação do espaço em "O Delfim" de José Cardoso Pires.

Intervençāo da Professora Cleonice Berardinelli, da Universidade Federal do Rio de Janeiro:

Louvando o trabalho, perguntou se "a caracterização da obra focalizada começa por ser o Neo-Realismo ou se este mascara outra Intenção".

Assim esclareceu a Professora Juril Nascimento Campelo:

- "Realmente, mascara; porém, o Autor não abre mão das técnicas neo-realistas: utiliza técnicas do "nouveau-roman", do "absurdo", etc.

Nova intervenção da Professora Cleonice Berardinelli, insistindo na indagação: "o romance começa por apresentar uma caracterizaçăo neo-realista?".

Ao que a Professora Juril Nascimento Campelo respondeu negativamente, acrescentando que tal idéia é apreendida à primeira vista apenas pelo leitor menos atento.

Intervenção do Professor Leodegário A. de Azevedo Filho, perguntando se a Professora Juril Nascimento Campelo "aproximou ocnceitos de Neo-Realismo e Surrealismo". E solicitando à comunicadora que etsabelecesse "a diferença entre o discurso ideológico e o discurso literário".

Resposta da Professora Juril Nascimento Campelo: "Embora se lembrasse da recomendação feita pelo Professor Leodegário A. de Azevedo FiIho, neste IV Encontro, na primeira Conferência, proferlda pelo Ilustre Professor, de que "nāo se misturassem os critérios de abordegem de uma obra 
literária". achou impossivel segui-la no caso de "O Delfim": o texto ultrapassa esteticamente certos preceitos do Surrealismo".

6.') Professora Maria Aparecida Santilli, da USP, que focalizou o tema: A Literatura Portuguesa perante a contextualidade cultural luso-afro-brasileira.

7.) Professora Miguelina Soifer, da Universidade Federal do Paraná, abordou o tema: Dinâmica do sonho em Fernando Pessoa.

Ao final da comunicaçāo, a Professora Miguelina Soifer destacou a atualidade do estudo de Fernando Pessoa.

O Presidente suspendeu os trabalhos e concedeu intervalo de 15 minutos.

Reabertura da sessão pelo Presidente, o qual solicitou entrega, por escrito, de qualquer proposta à Mesa, e convocou para integrá-la o Professor Juarez Távora de Freitas, da Faculdade de Letras de Belo Horizonte, Minas Gerais, que auxiliou no recolhimento das propostas.

Foram encaminhadas ao Presidente as seguintes propostas:

1.) do Professor Fernando Manoel de Mendonça, da UNESP. Assunto: sede do próximo Encontro na UNESP.

2.') do Professor Joel Pontes, da Universidade Federal de Pernambuco. Assunto: sede do próximo Encontro em Fortaleza, na Universidade Federal do Ceará.

3.') da Professora Cleonice Berardinelli, da U.F.R.J. Assunto: sede do próximo Encontro na PUC, Rio de Janeiro.

O Presidente pôs em discussão as três propostas, solicitando justificativas dos proponentes.

Intervenção do Professor Fernando Manoel de Mendonça, lembrando a disposição de que os Encontros se realizem de dois em dois anos.

O Presidente, em vista da preliminar levantada, lembrou a sugestão do Professor Dr. Antônio Soares Amora para que os Encontros passem a realizar-se anualmente. $E$ foi posta em discussão.

Intervenção do Professor Hélio Simōes, da Universidade Federal da Bahia, que argumentou favoravelmente, citando o exemplo dos congressos de professores franceses e americanos, realizados anualmente. E, dada a situaçāo grave da Literatura Portuguesa, propôs seja em 1977, O próximo Encontro.

Em votaçāo a referida proposta, foi ela aprovada por aclamação: o próximo Encontro será realizado em 1977. 
Intervenção do Professor Ildásio Tavares, da Universldade Federal da Bahia, argumentando que a proposta apresentada pelo Professor Fernando Manoel de Mendonça (número 1) em favor de Assis, para local de realizaఢ̧ão do próximo Encontro, devia ser retirada.

Ao que o Professor Fernando Manoel de Mendonça salientou a importância de esclarecimento sobre o interesse dos outros proponentes e suas Universidades em sediar o Encontro de 77 no Ceará.

O Professor Joel Pontes (autor da proposta número 2) manteve o pedido para Fortaleza.

Intervenção da Professora Cleonice Berardinelli, da Universidade Federal do Rio de Janeiro, esclarecendo que viera com poderes delegados para sugerir a PUC como local do próximo Encontro previsto para 1978, e, devido à alteração para 1977, não se achava autorizada a decidir.

Intervençăo do Professor Joel Pontes, da Universidade Federal de Pernambuco, lembrando a promessa, por ocasiāo do III Encontro, em Recife, de que a sede do vindouro seria o Ceará.

Intervenção do Professor Carlos Neves D'Alge, da Universidade Fedoral do Ceará, corroborando as palavras do Professor Joel Pontes e acrescentando a oportunidade de se deliberar também quanto ao local do Encontro de 1978.

Intervençāo do Professor Leodegário $A$. de Azevedo Filho, sugerindo que tal decisão seja reservada para o final do $V$ Encontro, no Ceará, sem antecipaçōes.

Intervençāo do Professor Carlos D'Alge, esclarecendo a necessidade de contar com o apoio das entidades oficiais no financiamento do próximo Encontro, e solicitando, ainda, o empenho do Ceará em tudo fazer para o total êxito do $V$ Encontro.

Intervençāo do Professor Fernando Manoel de Mendonça, chamando a atenção para o fato de que, alterado o prazo dos Encontros, de bienais para anuais, seria conveniente planejar com antecedência de dois anos o Encontro de 1978.

Intervenção do Professor Leodegário A. de Azevedo Filho, lembrando ao Professor Mendonça que a matéria já fora deliberada.

O Presidente esclareceu que: $10^{\circ}$ ) o próximo Encontro ficou decidido para a Universidade Federal do Ceará; 2.) $^{\circ}$ foi aventada a hipótese de se marcar também o local do Encontro de 1978. 
A seguir, pediu o encaminhamento de propostas concretas, relacionadas com o Encontro de 1978. Consultou o Plenário sobre a decisāo, de imediato, a respeito da sede. Constatou visualmente que a maioria decidira favoravelmente à discussão do assunto, ficando a resolução da sede entre a PUC e a UNESP.

Intervençāo do Professor Leodegário A. de Azevedo Filho, lembrando que no Rio de Janeiro há três Universidades oficlalizadas. Na hipótese de se realizar o VI Encontro naquela cidade, deveria haver um convênio entre as três, posto que tal empreendimento não pode cingir-se a uma Universidade e sim representar o empenho conjunto de todas existentes no Estado. $E$, encaminhando a votação, solicitou ao Plenário tempo para entrar em contato com os Diretores Caio Tácito e Afrānio Coutinho, a fim de deliberar sobre a possibilidade de um futuro Encontro no Rio, concedendo primazia à proposta de Assis.

Intervenção da Professora Cleonice Berardinelli: Pelo fato de não haver ela comparecido ao Encontro anterior, em Recife, gostaria de consultar o Professor Antônio Soares Amora a respeito da possibilldade de propor a sede da PUC para o próximo Encontro. Esclareceu também que a idéia partiu do próprio Diretor da PUC, que the fez várias perguntas sobre a natureza dos Encontros, e sugeriu o Rio de Janeiro, particularmente a PUC, para sede do futuro Encontro.

Intervenção do Professor Leodegário $A$. de Azevedo Filho: $O$ Encontro teria maior êxito se patrocinado em conjunto por todas as três Universidades oficializadas do Rio de Janeiro, e não apenas pela PUC. Acrescentou comentários sobre as magníficas instalaçōes da Universidade do Rio de Janeiro. - que contribuiria para a maior eficiência do Encontro.

O Presidente solicitou à Professora Cleonice Berardinelli que arrematasse seu pensamento. Ela concluiu, dizendo que se achava autorizada apenas a propor a sede da PUC, para o próximo Encontro, supondo-o em 1978. E aduziu que o Rio e Assis estavam em Idēnticas condiçōes, para patrociná-lo.

Intervenção do Professor Fernando Manoel de Mendonça: A proposta de Assis é conjunta com a UNES e com a USP, e conclamou, para tal afirmação, o testemunho do Professor Dr. Massaud Moisés que disso também tinha conhecimento. Frisou que a UNESP está em melhores condiçōes para promover o Encontro em 1978, lado a lado com a USP, tendo por sede Assis. Enalteceu as vantagens de localizaçăo geográfica da cidade de Assis e a facillidade de verba para a promoção. 
Intervenção do Professor Carlos D'Alge: O Encontro, em 1977, decidido a favor de Fortaleza, seŕ́ patrocinado também pela Universidade Estadual do Ceará, a ser inaugurada brevemente pelo Presidente Geisel, pela Universidade de Fortaleza (particular), Junto à Universidade Federal do Ceará. Propôs, a seguir, a última semana de outubro de 77 , para época do próximo.

O Presidente opinou que a questão de data dos Encontros 6 declsão dos organizadores.

Irtervenção do Professor Ildéslo Tavares, encaminhando a votação a favor de Assis.

O Presidente submeteu à votação a proposta número 1 (Assis), obtendo-se o seguinte resultado: 36 votos favorávels e 6 abstençōes. Assim sendo, - Presidente indicou oficialmente a Faculdade de Assis para sede do VI Encontro, em 1978.

Intervenção do Professor Fernando Manoel de Mendonça: Na UNESP patrocinarăo o VI Encontro a Faculdade de Assis e a de Marilia, distante apenas $70 \mathrm{~km}$.

O Presidente, dando seqũência à leitura das propostas encaminhadas à Mesa, apresentou a $4 . \therefore$ de autoria do Professor Artur Anselmo de Oliveira Soares, da UFMG, com o seguinte teor: seja constituldo um grupo permanente (eleito anual ou bienalmente, conforme a periodicidade dos Encontros) para estudo dos problemas relacionados com a difusão do livro "Português" (lato sensu) nas Universidades Braslleiras, trabalhando em colaboraçăo com as representaçōes culturals dos Estados de língua portuguesa, e mantendo intercámbio com professores interessados.

O Presidente colocou a citada proposta em votaçăo, tendo sido aprovada por unanimidade.

A 5." proposta foi do Professor Heltor Megale, da Faculdade Camilo Castelo Branco, de São Paulo. Assunto: Modificação da modalidade dos futuros Encontros, propondo a formação de grupos para debates e a aplicaçăo da técnica de dinâmica de grupos, para discussåo de assuntos clentíflcos o práticos.

O Presidente encaminhou a proposta como sugestão para o próximo Encontro. 
Intervenção do Professor Leodegário A. de Azevedo Filho, consultando - Presidente sobre a possibilidade de tempo para discussão de assuntos gerais.

Devido ao adiantado da hora, o Presidente consultou o Coordenador Geral, Professor Dr. David Antônio da Silva Carneiro, a respeito da sessão de encerramento.

Intervenção do Professor Artur Anselmo, sollcitando a indicação do grupo de trabalho sugerido em sua proposta (número 4) e já aprovada por unanimidade.

O Presidente encaminhou ao Professor Carlos D'Alge, da Universidado Federal do Ceará, a identificação dos elementos que constituirāo o referido grupo, por ocasiāo do vindouro Encontro, em 1977.

A 6.' proposta, do Professor Ildásio Tavares, da Universidade Federal da Bahia, tratou do temário do próximo Encontro, que deve versar sobre problemas inerentes ao ensino da Literatura Portuguesa no Brasil, visando a aperfeiçoátlo e melhorállo em sentido prático de sua problemática no nosso Pais.

Intervençāo do Professor Leodegário A. de Azevedo Filho, sugerindo que as comunicaçōes apresentadas nos futuros Encontros acrescentem algo de original, nāo permanecendo nas citaçōes já conhecidas, cansativas pela redundância.

O Presidente, Professor Naief Safady, da UFMG, agradeceu a atençāo de todos, e considerou encerrada a sessão, que secretariel, e da qual fiz o presente relatório.

Curitiba, 27 de outubro de 1976.

(A.) Maria Carolina Brasileiro de Castro, da Faculdade de Filosofia, Ciênclas e Letras de Lavras, Minas Gerais.

\section{COMUNICAÇÃO PROPOSTA PELO PROF. DR. MASSAUD MOISES}

(Aprovada por aclamação na sessão de 27-10-1976)

O signatário propōe que o IV Encontro de Professores Brasileiros de Lite- 